\title{
UNITED KINGDOM HOSPITAL LIBRARY SERVICES
}

\begin{abstract}
A PILOT survey of hospital library services has been made by an independent committee, of which Mr. J. A. M. Ellison-Macartney was chairman, sponsored by the King Edward's Hospital Fund for London (Hospital Library Services : a Pilot Survey. Report of an Independent Committee sponsored by King Edward's Hospital Fund for London. Pp. 56. London : King Edward's Hospital Fund for London, 1959. 2s. 6d.). Its report, now published, directs attention to the apathy of some hospital authorities and officials and to the inadequacy of much accommodation, but the greatest weakness uncovered by the survey was the quality of the books provided by the smaller voluntary organizations. The Committee believes that ideally the public libraries should be the major source of supply of books and that this should become a recognized function and duty of all such libraries. Nevertheless, the survey also revealed the great strength which lies in the supply of voluntary lib. rarians, and the Committee also believes that ideally the staffing of hospital libraries could be undertaken by voluntary organizations in conjunction with the local public libraries supplying the majority of the books.

In general, hospital library services require a new look, and the Committee recommends that hospital authorities at the highest level should regard it as an essential duty to see that an efficient service is provided in all hospitals (except where special circum. stances render it undesirable) rather than leave the decision to be taken at a lower administrative level. Far greater positive interest in the library service
\end{abstract}

should be taken at all levels of hospital authorities and staffs ; it should no longer be left in the main to volu atary helpers with the minimum of support in inter'est, funds and equipment. All architects' plans for new hospitals or extensions to existing hospita $s$ should in future include library accommodation conveniently sited, and certain standards for accommodation and equipment are recommended for consideration. In particular, it is emphasized that because most library services are likely to continue to be run by volunteers, particularly women of middle age, the siting of library accommodation, height of shelves, weight of trolleys, heating, lighting and ventilation are of paramount importance. The standard of books provided should be that of books provided to the general public by the best public libraries, and the Committee recommends that for a hospital of average size, annual expenditure on new books should be not less than 6s. per bed. All hospital library services should include the provision of books to hospital staffs, and the Committee suggests that valuable training courses run by St. JohnRed Cross should be open to all hospital librarians. The question whether books are capable of carrying tubereulosis infection requires scientific ir.vestigation and an authoritative pronouncement. The Committee believes that with the existing variety of library services, full efficiency cannot be attained on a basis of less than $£ 1$ per bed per annum at present prices, or $£ 3$ per bed per annum if salaries, but not overheads, are included.

\section{THE ATLANTIC EEL PROBLEM}

$\mathrm{R}$ ECENTLY Tucker ${ }^{1}$ published his view on the origin of the Europoan eels. He advocates the revolutionary theory that all the European eels are the offspring of American parent stock. His argument is presented under three headings, of which the first, dealing with the return of the silver eels towards their breeding places, is in my opinion the most important one. Therefore, special attention will be paid to this section of Tucker's article.

Tucker begins by laying stress on the fact that the European silver eel is already well advanced towards being a reproductive oceanic fish despite the long journey which supposedly lies before it, this in marked contrast with the American silver eel, which is relatively retarded. The conclusion is drawn that this is just the reverse of what one would anticipate, taking into consideration the distance it has to go.

The impossibility of providing exact information on the timo required to become a reproductive fish renders this subject elusive of criticism and debate. Comparison with other species of fish is moreover of little value; one should in my opinion concentrate on the features and habits of the European silver eel itself.

For the same reason the next paragraph dealing with the comparison of external features of both species under consideration cannot lead to an irrefutable conclusion. The only reasonable conclusion one could draw from the differences mentioned is, in my opinion, that there is every reason for believing in the existence of two really distinct species, which is just the opposite of what Tucker tries to demonstrate.

According to Tucker, the longevity of silver eels in captivity is irrelevant. We know, however, that the silver eels, kept in the tanks of the eel merchants, are always on the move; when the water in the tanks is in motion, the silver eels are swimming in the upstream direction. Despite the rather unfavourable conditions in the tanks, the silver eels go on swimming for months and months in succession. It is certainly a remarkable fact that such eels are, even after a period of prolonged storage, fat enough to be attractive for the consumer, for they can easily be sold at a fair price. This demonstrates that silver eels are able to move over huge distances without degeneration of their tissues. It seems therefore that this matter cannot be considered as irrelevant to the subject under discussion.

Two other items in Tucker's article are open to doubt :

(1) If one assumes with Tucker that the migrating eels must use a very simple orientation mechanism 